Revista Iberoamericana, Vol. LXXIV, Núm. 224, Julio-Septiembre 2008, 675-683

\title{
NEM REGIONAL NEM NACIONAL, MAS INTERNACIONAL: A QUADRAGÉSIMA PORTA, ROMANCE DE JOSÉ GERALDO VIEIRA
}

POR

\author{
Vivaldo Andrade dos Santos \\ Georgetown University
}

\section{I. À MARgEM do BrasiL, NO CENTRO DA EUROPA}

José Geraldo Vieira ${ }^{1}$ (1897-1977) por muitos anos tem sido esquecido pela crítica literária brasileira. Se por um lado, a crítica concorda na sua importância dentro da literatura brasileira, o foco da crítica tem sido de grande limitação, de análises simples e generalizadas da sua obra. Alfredo Bosi assinala que Vieira ocupa uma posição marginal na literatura brasileira, visto que seus romances se distanciam do "romance regionalista," sendo seus livros “os mais cosmopolitas que já se escreveram em língua portuguesa” (412). ${ }^{2}$

Neste ensaio, analiso o romance de Vieira, A Quadragésima Porta, publicado em 1943. Esse desconforto que o romance de Vieira cria para a crítica literária brasileira é examinado a partir de dois pontos de vista críticos relativamente opostos: o de Antonio Candido e Sérgio Milliet. O intuito nosso neste artigo é trazer José Geraldo Vieira à cena e colocar em debate o modernismo, pensando na importância do movimento como construção ideológica do cânon literário brasileiro.

Ahistória de AQuadragésima Porta começa em Portugal e centra-se na vida de Gonçalo e de Albano, neto do velho Albano, prominente senhor português, de raízes abastadas, de

1 José Geraldo Manuel Germano Correia Vieira Machado Drumond da Costa Fortuna nasceu no Rio de Janeiro em 1897 e faleceu em São Paulo em 1977. Filho de pais açorianos, Vieira fez seus primeiros estudos no Rio de Janeiro, indo para Paris em 1911, onde estudou humanidades no Liceu Condorcet. Em 1914 retorna ao Brasil, ingressando na Faculdade da Praia de Santa Luzia, onde cursou Medicina. É autor de Triste Epigrama, poema em prosa (1919) e dos contos Ronda de Deslumbramento (1922), marcadamente influenciados pelo peso da estética penumbrista dos últimos anos da belle époque. Entre 1920 e 1922 estudou radiologia em Paris e em Berlin, viajando depois pela Europa. Após retornar ao Brasil, dedicou sua vida à medicina e literatura. Foi tradutor de Joyce, Remarque, Thomas Merton, Hemingway, Stendhal, Tolstói, Dostoievski, Joyce, Pirandello, Steinbeck, e outros. Entre seus romances encontram-se A Mulher Que Fugiu de Sodona (1933), Território Humano (1936), A Quadragésima Porta (1943), A Túnica e os Dados (1947), A Ladeira da Memória (1950), O Albatroz (1952), Terreno Baldio (1961), Paralelo 16; Brasília (1966) e o livro de poemas A Mansarda Branca (1974).

2 Afrânio Coutinho afirma que "É de solidão a trajetória de José Geraldo Vieira. E talvez o lema de Camus pudesse a ele se aplicar: solitário e solidário” (344). 
filhos e parentes educados na Inglaterra, freqüentadores de salões pariesiences, amantes da alta cultura, donos de grandes quintas, casas em Lisboa e Paris, palacetes no interior do país, propriedade no sul da França com campo de pólo, campos de golf, e inclusive uma pista de aviação, aos quais soma-se a posse de uma usina hidroelétrica, uma agência telegráfos, e co-propriedade de companhias internacionais de petróleo. A esse quadro somase o universo econômico europeu das primeiras décadas do século xx, o fluxo de capitais em altos investimentos nas bolsas de valores de Londres, Lisboa, Roma e Paris. A Europa da primeira metade do século xx é o grande pano de fundo da história, centrando-se a ação em Portugal, e especialmente Paris. O romance, de um modo geral, gira em torno da “D-U”, “Despachos Urgentes”, agência de notícias que dá conta dos acontecimentos dos eventos históricos mundiais entre 1914 e 1943, como Primeira Grande Guerra, a Revolução Russa, o surgimento do Comunismo e do Fascismo, a Guerra Civil Espanhola, A Invasão da Etiópia, A Segunda Grande Guerra até a caída da França frente à Alemanha.

A concepção ficcional de Vieira destoa da tradição ficcional brasileira da época, especialmente o romance das décadas de 30 e 40. De um lado, a tradição regionalista, centrada na temática do sertão nordestino, no tratamento das culturas locais, da terra, ou da nostalgia do campo frente ao processo de modernização com a transição do engenho ao engenho, do qual José Américo de Almeida, José Lins do Rego, Raquel de Queirós; da denúncia da exploração humana, presente nos romances sobre o interior da Bahia de Jorge Amado, ou nos costumes locais do território gaúcho, nos romances de Érico Veríssimo, são os maiores expoentes. ${ }^{3}$ Do outro lado, a tradição do romance intimista, memorialista ou de tendência psicológica, da qual fazem parte o Graciliano Ramos, Otávio de Farias, Cornélio Pena, Lúcio Cardoso, entre outros.

De forma ambiciosa, José Geraldo Vieira define A Quadragésima Porta como um romance ecumênico. Isto é sugerido na apresentação do livro, onde o autor assinala que seu intento não é "de romance cosmopolita, mas de encruzilhada ecumênica e trazem múltiplos elementos do caráter humano - hábitos, vícios, virtudes, emoções, compromissos e emancipações” (7-8). Este intento é reafirmado em entrevista, onde o autor reitera que "É por isso que não me satisfaço em ser romancista de bairro, duma cidade, dum país, duma época. Quero o romance têmporo-espacial, um estilo em redoma que abarque tudo, mero recesso gráfico e acústico da contemporaneidade total” (Garcia 242).

Não passa despecebido ao leitor, no “Átrio,” ou na apresentação do livro, o desejo de Vieira de estabelecer uma ligação direta do seu projeto ficcional com uma genealogia literária ocidental da maior tradição, incluindo Balzac, Pirandello, Kafka, Huxley, Joyce, Katherine Mansfield, Goethe, Proust, entre outros. Ao situar-se nessa genealógica, Vieira abre caminho para a discussão do cânon, ecoando Harold Bloom para quem "Canon is primarily manifested as the anxiety of influence that forms and malforms each new writing that aspires to permanence" (12). Observe-se que o desejo de permanência de Vieira de alinhar-se à tradição ocidental é, também, o desejo de ultrapassar a dimensão espaço-temporal e permanecer na história literária, visto que "the desire to write greatly is the desire to be elsewhere, in a time and place of one's own, in a originality that must compo und with inheritance, with the anxiety of influece”. Se

3 Ver Moraes; Galvão 65-86. 
seguirmos o argumento de Bloom que acredita que reconhecer a tradição é reconhecer seu valor intrínsico de originalidade para espelhar-se e buscar na mesma o estímulo de genialidade, Vieira, dentro do contexto da literatura brasileira, antecipa ao leitor sua escolha estética: uma literatura internacional, porém, exclusivamente definida pelo cânon ocidental.

Este desejo de internacionalização transfere-se a todo ambiente do romance, ao qual se soma personagens de ascendência nobre, embaixadores, e junto a isso todo um universo cultural revelador de tal nobreza:

Cada um desses ingleses aí a bebericar gim ou uísque, a fumar Abdulla ou Partagas, trazia uma talhada de meridianos. EAlbano tinha que ir depois comprar Mother India, de Katherine Mayo, ou conseguir emprestado The Prince of India, de Barton. Na sala de café da D-U tirava das prateleiras ou dos ganchos, coleções de jornais e revistas que eram uma verdadeira Invitation au voyage: The Hindu, de Masdrasta, Foreign Affairs, Japan Advertiser, ASIA, China Weekly Review, etc. [...] Os nomes soavam bem: Lorde Lattimore, um plantador de chá. O’Malley, um esquálido e escanhoado magnata do petróleo na Palestina. Ovelho Lawton, comanditário do marajá de Johore, em plantações de borracha. O obeso Snow, banqueiro na Birmânia. E assim, outros. [...] Diáfano, translúcido, quase tropical, era o ambiente da ex-embaixatriz Martin-Ducroz, cuja esfera de influência conglomerava americanos do centro e do sul. Michaël o tinha apelidado Gulfstream. Imperava aí o temperamento da Ibéria transplantada: argentinos, chilenos, uruguaios, brasileiros, colombianos, peruanos, guatematelenses, costariquenhos e mexicanos. (232)

A Quadragésima Porta é um texto que busca ser internacional ou cosmopolita tanto no nível temático como discursivo, da linguagem:

Sem soltar o braço de Brígida, Gonçalo olhava para as portas e para o alto da escada. Percorreu tudo, desde a cozinha à "sala que não abre nunca" e subiu para revistar os quartos e os salões. Ria, fazia um ar de espera, a ver se lhe diziam; encaminhou-se para o jardim, até as parreiras, foi espiar em volta do moinho, onde afinal encontrou a ama com o garoto. Mas, industriada pela tia Mariana, a ama fugia-lhe. Mal a alcançava, ela desvencilhava-se, obedecendo sempre aos gestos e à voz da tia Mariana.

-Gestatten Sie, bitte, ich bin sein Vater! Io sono il babo! I am the daddy! Mais, nom de Dieu, c'est mon enfant! (Dizia assim, em diversos idiomas porque achava a ama com cara de estrangeira e não atinava com a nacionalidade dela). (75)

Importa salientar que o aspecto internacional da linguagem marcado pela grande quantidade de expressões da língua francesa e inglesa, o variado número de neologimos e vocabulário técnico, somado à linguagem erudita que atravessa o romance, faz-nos pensar na definição do dialogismo ou plurilingüismo de Mikhail Bakhtin, para quem “O prosador-romancista não elimina as intenções alheias da língua feita de diferentes linguagens de suas obras, não destrói as perspectivas sócio-ideológicas (mundos e micromundos sócio-ideológicos) que se desenvolve além das linguagens do plurilingüismo, ele as introduz em sua obra" (105). No entanto, vale dizer que se a enxurrada de estrangeirismos e de citações eruditas, presentes no livro, apontam para o plurilingüismo, o discurso dialógico não se efetua de forma completa, uma vez que a escolha da linguagem culta deixa de fora quaisquer 
ocorrências da linguagem popular. ${ }^{4}$ A linguagem do romance reflete assim, lembrando Alfredo Bosi, "o burguês culto e sofisticado que respira ondas contínuas e crescentes de informação” (412). Uma sofisticação que custará caro ao autor de A Quadragésima Porta, como veremos a seguir. ${ }^{5}$

\section{ENTRE A FORTUNA E O INFORTÚNIO CRÍTICO}

Seporumlado esse intento de pensarum romancebrasileiro comuma formainternacionalé, especialmentena sua concepção espacial e temática, motivo de reconhecimento de originalidade por muitos, a crítica literária sociológica não deixa por menos. Os fundamentos desse desejo de universalização é colocado em cheque. Antonio Candido, por exemplo, um dos críticos mais duros de Vieira, publica em 1945 o artigo “O Romance da Nostalgia Burguesa”, sobre A Quadragésima Porta. Candido não poupa o escritor carioca, dizendo:

Ora, nascido do cosmopolitismo da burguesia litorânea, este romance não é ecumênico, segundo pretende. Nem no sentido horizontal, - de sobrepor-se às fronteiras dos povos, nem no vertical, - de sobrepor-se às fronteiras de classes. É o romance de uma classe, a alta burguesia internacionalizada, dotada, graças aos recursos materiais, de grande mobilidade no espaço, e dos clientes que lhe servem de satélites: artistas, intelectuais, servidores. O povo permanece significativamente ausente deste livro que ambiciona as fronteiras do ecúmeno... (37)

Candido situa o romance de Vieira como parte da tradição intelectual brasileira das primeiras décadas do século xx, da chamada belle époque, inclinada à fascinação pela cultura européia e descaso pela cultura e realidade nacional. ${ }^{6} \mathrm{O}$ crítico desarma a intenção do autor de

4 Bakhtin, no seu estudo sobre o romance, assinala que a particularidade da linguagem romanesca está sempre condicionada a um ponto de vista particular sobre a realidade, consequentemente aspirando “a uma significação social”. Segundo ele, “o sujeito que fala no romance é um homem essencialmente social, historicamente concreto e definido e seu discurso é uma linguagem social (ainda que em embrião), e não um “dialeto individual” (134-5).

5 Hélio Pólvora assinala o dilema do escritor com respeito à escolha da linguagem romanesca: "Se o romancista tentava captar a expressão oral, transpondo falas e costumes, incidia no caipirismo - que é uma forma de ficção artificial e artificiosa. O localismo na ficção é a primeira instância da regionalidade e deriva algumas vezes para o provincianismo, da mesma maneira que o ficcionismo ecumênico, ou cosmopolita, deforma o romance de pendor ou de teor universalizante. Talvez por isso um romance bem arquitetado, como A Quadragésima Porta, do paulista José Geraldo Vieira, esteja hoje esquecido".

6 A Quadragésima Porta me parece exprimir algumas das atitudes e estados de espírito de certa burguesia litorânea, que pesou decisivamente na orientação política, artística e literária do Brasil, no período que vai do Encilhamento ao crack de 1929. Que se nutria de valores europeus e considerava o seu país - no qual se sentia despaisada - como uma linha pontilhada ao longo da costa, apoiandose na enorme de massa de uma terra exótica, de que lhe falavam os contos de Afonso Arinos. Que tinha a vocação do cosmopolitismos e o culto da viagem à Europa, donde importava tudo, desde o leite condensado e a manteiga suíça. O livro o sr. José Geraldo Vieira é o mais brilhante sintoma e, por ventura, a supremaafirmação literária dessa classe sem consciência efetiva, em equilíbrio instável sobre uma economia semi colonial, marginalizada culturalmente por um desejo doentio de participar, custasse o que custasse, das radiações do ocidente europeu” (32). 
definir seu romance como “ecumênico”, relativizando o conceito de “internacionalização” a partir do conceito de "classe social”. Para Candido, tal internacionalidade é construída sobre uma base material, econômica, que permite intelectuais e autores como o de AQuadragésima Porta pensar a experiência individual ou de um grupo social como experiência coletiva. Esta relativização do caráter internacional é vista também na ação dos personagens, como na crítica a ideologia religiosa presente no texto. Segundo Candido, o romance, embora não sendo um "romance católico”, é construído sobre uma matriz dessa tradição. ${ }^{7} \mathrm{O}$ crítico atenta para o fato de que so sentido da bondade e da virtude, expressos nas ações dos membros da família do velho Albano, são projeções de uma burguesia altamente capacitada por suas condições materiais, econômicas. Ou seja, toda a experiência coletiva é, em essência, uma preocupação com o crescimento individual, do desenvolvimento da "alma" individual, ilustrado pelo personagem de Gonçalo que vai à Rússia, embarca nos ideais da Revolução de 1917, “experimenta”, sofre, acredita na validade da sua participação, e volta à sua terra natal para manter o seu status quo (36). Ou seja, a experiência da guerra nada mais é do que a capitalização intelectual individual. Em que "tudo se transforma em matéria de experiência pessoal, de aventura da personalidade e da sua bela alma”. Onde, "o homem se torna de fato a medida de todas as coisas", traduzido em "um essencialismo personalista” (37).

O universal é assim posto em questão pelo elemento classe. Encontramos na rejeição de Candido ao romance de Vieira a marca da crítica sociológica, em particular de linha marxista que busca "to provide a materialist explanation of the bases of literary value" (Eagleton 162), desafiando e colocando ao crivo as formas literárias definidas puramente pelo seu valor estético intrínseco.

Alógica de Candido coincide com a tradição marxista que vênas formas de representação da cultura capitalista, no romance realista e moderno, por exemplo, "a radical split between the private and the public, between the poetic and the political, between what we have come to think of as the domain of sexuality and the unconscious and that of the public world of classes, of the economic, and of secular power" (Jameson 69). Candido, agudamente, assinala o vir-a-ser do romance de Vieira a partir de uma aproximação analítica que aborda seu objeto de estudo dentro de um marco histórico e social. ${ }^{8} \mathrm{O}$ leitor familiarizado com a obra de Candido observa os fundamentos desta concepção literária já na sua Formação da Literatura Brasileira, onde a literatura é um sistema orgânico, articulado pelo escritor, a

7 Refiro-me aqui ao romance católico, gênero que coexistiu com o romance instrospectivo e social da década de 30, nascido em torno da revista Ordem, das idéias de Jackson de Figueiredo, e que inclui a produção literária de Octávio de Faria, Augusto Frederico Schmidt, Murilo Mendes, Tristão de Ataíde (Alceu Amoroso Lima), entre outros. Ver Lafetá.

8 "Literary works are not mysteriously inspired, or explicable simply in terms of their author's psychology. They are forms of perception, particular ways of seeing the world; and as such they have a relation to that dominant way of seeing the world which is the 'social mentality' or ideology of an age. That ideology, in turn, is the product of the concret social relation into which men enter at a particular time and place; it is the way those class-relations are experienced, legitimated and perpetuaded" (Eagleton, Marxism 6). 
obra e seu público. ${ }^{9}$ É a literatura o espaço simbólico de configuração da realidade históricosocial "por meio do qual as veleidades mais profundas do indivíduo se transformam em elementos de contato entre homens, e de interpretação das diferentes esferas da realidade" (Formação 17).

Do ponto de vista da compreensão do modernismo, é mais significativo trazer ao âmbito da discussão aqui a leitura de Candido como estabelecedor de um paradigma de leitura formador do cânon literário brasileiro. ${ }^{10}$ Para contrastar, tomemos por exemplo a leitura que faz Sérgio Milliet sobre o romance de Vieira:

$1^{\circ}$ Janeiro 1944 - A literatura brasileira destes últimos anos vem se esforçando por aprender em seus múltiplos aspectos a realidade nacional. Há em quase todos os nossos escritores uma procura de comunhão com a terra, a gente, os problemas do Brasil [...] Por isso mesmo estranhamos um pouco o romance de José Geraldo Vieira que se caracteriza exatamente por uma tendência diferente, para o assunto internacional, universal, e a língua de boas raízes portuguesas. (11)

Milliet assinala na sua entrada a tendência regionalista e do realismo social da literatura brasileira do decênio de 30 e começo de 40, e aponta o caráter "estranho" que o romance de Vieira apresenta: o seu aspecto internacional. Importa aqui enfatizar o elemento universalizante da temática bem como o aspecto lingüístico (“de boas raízes portuguesas”), distantes e distintos da proposta regionalista que dita o romance nacional da época. Na sua exaltação de A Quadragésima Porta, Milliet continua, dizendo que o ano de 1943 “deu-nos uma farta colheita de boa ficção [...] e agora esse livro maduro, desigual, mas profundo, sugestivo e cultíssimo de José Geraldo Vieira. Com ele nossa literatura se enriquece de uma nova solução. Com ele iniciamos uma nova etapa que terá sem dúvida seus entusiastas” (17). Para o crítico, a proposta ficcional de Vieira é a “nova solução” para resolver o sentimento periférico tão caro a um setor da intelectualidade brasileira: "Rompemos nosso isolacionismo e entramos na agitação do mundo. Saímos da aldeia para a metrópole”.

Vale notar que a visão de Milliet coincide com esta intelectualidade, criticada acima por Candido “por suspirar pela Europa”, lembrando Drummond. O autor do Diário Crítico se reconhece na realidade representada no romance de Vieira: "Essa Europa que o autor escolhe para cenário da vida de uma grande família portuguesa, educada nas universidades inglesas e passeando pelos salões de Paris sua projeção mundana, financeira e intelectual, eu a reconheço com saudades" (14).

Se Milliet se encontra no romance por meio do elemento saudosista, para Candido, como vimos acima, é o oposto: a realidade representada no romance é para ser negada. Dentro

9 Segundo Candido, “a existência de um conjunto de produtores literários, mais ou menos conscientes do seu papel; um conjunto de receptores, formando os diferentes tipos de públicos, sem os quais a obra não vive; um mecanismo transmissor (de modo geral, uma linguagem, traduzida em estilos), que liga uns e outros” (Formação 17).

10 Vale dizer que, embora tecendo uma dura crítica ao romance, Candido reconhece no livro momentos de grande expressão, como a presença do anjo que acompanha o personagem de Albano: "Graças a ele ganhamos uma das páginas incontestavelmente mais belas da nossa literatura” ("O Romance...” 42). 
desta perspectiva, A Quadragésima Porta surge como um espelho no qual se reconhece ou não. Enquanto Milliet olha nesse espelho e se encontra no passado, Candido, por outro lado, assinala a necessidade de quebrar o espelho, elemento fixador, e pensa um sistema ativo, em que a forma literária representacional é um todo movido por constantes tensões internas e externas, capazes assim de captar ou assinalar as transformações (necessárias) da realidade social. ${ }^{11}$

\section{A TERCEIRA MARGEM}

A crítica já apontou elementos positivos e negativos de A Quadragésima Porta como romance. Entre os acertos romancistas de Vieira, são enfatizados, de um modo geral, o aspecto universalista e cosmopolita do romance. A artificialidade da linguagem, o barroquismo ou jogos verbais, o desenvolvimento e a representação limitada da psicologia dos personagens, o excesso de intelectualismo são exemplos de falhas apontadas no livro. Interessa-nos reler Vieira para ir além das suas falhas de composição e sua matriz ideológica. Vale, pois, examinar as questões estético-ideológicas que o livro propõe para o modernismo brasileiro.

Problema 1: Vieira, ao pensar A Quadragésima Porta como romance ecumênico, complica argumentos marxistas, como proposto por Roberto Schwarz sobre a sua crítica ao "discurso da modernização conservadora", presente na formulação oswaldiana da antropofagia e da poesia "Pau-brasil”: "a justaposição de elementos próprios ao BrasilColônia e ao Brasil burguês, e a elevação do produto - desconjuntado por definição - à dignidade de alegoria do país” (12). ${ }^{12}$ Ao deslocar para a Europa o romance, Vieira apaga as tensões internas que caracterizam os paradoxos da modernidade brasileira, e que a crítica marxista de Schwarz espera poder encontrar. Vale dizer que Vieira apaga um dos elementos da relação dialética (isto é, a condição colonial), deixando apenas o elemento burguês (representado pelos sinais da modernização capitalista, naturalizados pelo universo social dos personagens do romance). Ao fazer isso, Vieira não somente mina o argumento de Schwarz como também coloca abaixo qualquer possibilidade de pensar alegoricamente seu romance. Somos forçados assim a pensar a literatura fora do paradigma alegórico.

Problema 2: Antonio Candido assinala a "ausência do Brasil” no romance, dizendo que "O que mais impressiona na "Quadragésima Porta" é o seu desligamento total do Brasil, dos nossos problemas, da nossa maneira de ver os problemas, - como desligada do Brasil era e ainda é a classe de que ela é a expressão e o símbolo” (“O Romance...” 43). Assim, ao situar A Quadragésima Porta no continente europeu, Vieira aparentemente "resolve” a questão da dependência, uma vez que os elementos partícipes na construção do ficcional

11 A perspectiva de Candido, de algum modo, coincide com a crítica marxista contemporânea, como as formulações de Jameson, para quem a literatura do "Terceiro Mundo" onde "the story of the private individual destiny is always an allegory of the embattled situation of the public third-world culture and society” (Jameson 69). Ver também Eagleton, Marxism.

12 Um argumento que vai de encontro às “idéias fora-do-lugar", exemplificado na sua forma original pela implementação das idéias liberais do século xix numa sociedade escravocrata ao descompasso entre os símbolos de modernização entrelaçados aos elementos de uma realidade periférica e arcaica, como é caso da brasileira. Ver Schwarz, “As Idéias...”. 
“naturalizam-se” no espaço de sua enunciação. Ou seja, a modernidade da linguagem casa-se à modernidade da Europa.

Esta reflexão sobre A Quadragésima Porta, de José Geraldo Vieira, tem como horizonte certas discussões teóricas de Fredric Jameson sobre capitalismo, globalização e posmodernismo. Nosso argumento é que, primeiro, Vieira se distancia do projeto estético de identidade nacional, defendido pelos escritores modernistas da década de 1920 e regionalistas de 1930, bem como da ficção psicológica contemporânea sua. Ao propor um "romance internacional”, Vieira coloca em discussão sobre o fim das literaturas nacionais. É preciso dizer que sua definição da literatura continua presa ainda à visão da "alta literatura", ao cânon ocidental. Os germes de uma noção de "literatura globalizada”, nascida de toda experiência humana (de raça, gênero ou classe) e criada a partir das condições materiais que o desenvolvimento capitalista promove, fica “à porta” de A Quadragésima Porta (ver Santos). Contudo, neste momento em que a crítica busca repensar o papel e a noção do discurso literário, o surgimento dos estudos culturais, de redefinição do marxismo num contexto do capitalismo avançado, o romance de José Geraldo Vieira merece uma nova apreciação crítica para melhor compreender sua proposta estética, sua ideologia e a ideologia do modernismo modernismo.

OBRAS CITADAS

Aguiar, Flávio, org. Antonio Candido: Pensamento e Militância. São Paulo: Fundação Perseu Abramo, Humanitas/FFLCH/USP, 1999.

Bakhtin, Mikhail. Questões de Literatura e de Estética: a Teoria do Romance. São Paulo: Hucitec; Unesp, 1998.

Bloom, Harold. The Western Canon: The Books and School of the Ages. New York: Harcourt Brace, 1994.

Bosi, Alfredo. História Concisa da Literatura Brasileira. 32 ed. São Paulo: Cultrix, 1994.

Candido, Antonio. Formação da Literatura Brasileira: Momentos Decisivos. Vol. I. São Paulo: Martins, 1959. “O Romance da Nostalgia Burgesa”. Brigada Ligeira. São Paulo: Martins, 1945.

Coutinho, Afrânio. A Literatura no Brasil. Vol. V. 2 ed. Modernismo. Rio de Janeiro: Sul Americana, 1970.

Eagleton, Terry. Criticism \& Ideology. London: Verso, 1984. Marxism and Literary Criticism. Berkeley: U of California P, 1976.

Galvão, Walnice Nogueira. “De Sertões e Jagunços”. Saco de Gatos. 2 ed. São Paulo: Duas Cidades, 1976.

Garcia, Márcia Aparecida. José Geraldo Vieira (Fortuna Crítica). Dissertação de Mestrado. Assis: Faculdade de Ciências e Letras de Assis-UNESP, 2003.

Jameson, Fredric. “Third-World Literature in the Era of Multinational Capitalism”. Social Text 15 (Fall, 1986): 65-88.

Lafetá, João Luís. 1930: A Crítica e o Modernismo. São Paulo: Duas Cidades, 1974.

Milliet, Sérgio. Diário Crítico. 2 ed. São Paulo: Edusp, 1981. 
Pólvora, Hélio. “José Lins do Rego” <http://www.revista.agulha.nom.br/jlrego. html\#polvora>

Moraes, Lígia Chiapini Leite de. Regionalismo e Modernismo. São Paulo: Ática, 1978.

Santos, Lídia. Kitsch tropical: los medios en la literatura y el arte en América Latina. Madrid: Iberoamerica, 2004.

"Global ou Local: O Tropicalismo Brasileiro e a Presença da Cultura de Massa na Narrativa da América Hispânica e do Caribe”. Revista Iberoamericana LXIV/182-183 (Enero-Junio, 1998): 37-53.

Schwarz, Roberto. “As Idéias Fora do Lugar”. Ao Vencedor As Batatas. São Paulo: Duas Cidades, 2000. 9-32.

“A Carroça, o Bonde e o Poeta Modernista”. Que Horas São? São Paulo: Companhia das Letras, 1989. 11-28.

Vieira, José Geraldo. A Quadragésima Porta. 3 ed. São Paulo: Martins, 1968. 